Pacific Journal of Mathematics

A VARIANCE PROPERTY FOR ARITHMETIC FUNCTIONS 


\title{
A VARIANCE PROPERTY FOR ARITHMETIC FUNCTIONS
}

\author{
JOSEPH E. COLLISON
}

A pivotal point for certain problems in probabilistic number theory is that there exists a positive constant $c$ such that for every member $f$ of the family of additive complex valued arithmetic functions

$$
\sum_{m \leqq n}|f(m)-A(n)|^{2} \leqq c n D^{2}(n)
$$

where

$$
A(n)=\sum_{p^{\alpha} \leqq n} f\left(p^{\alpha}\right) p^{-\alpha}\left(1-p^{-1}\right)
$$

and

$$
D^{2}(n)=\sum_{p^{\alpha} \leqq n}\left|f\left(p^{\alpha}\right)\right|^{2} p^{-\alpha}\left(1-p^{-1}\right),
$$

$p^{\alpha}$ being a power of a prime number. This paper considers the extension of this property in two directions suggested by Harold N. Shapiro. First, an investigation is made of when this property holds for weight functions other than $w(m) \equiv 1$. Second, it is shown that this property can be extended to various nonadditive arithmetic functions.

1. Preliminaries. Let $p$ and $q$ represent prime numbers while $m, n, \nu, \alpha$ and $\beta$ represent positive integers. Nonnegative weight functions are represented by $w$ and complex valued arithmetic functions by $f$. Then $f$ is said to possess the Variance Property with respect to $w$ if

$$
\sum_{m \leqq n} w(m)|f(m)-A(n)|^{2} \leqq c D^{2}(n) \sum_{m \leqq n} w(m)
$$

for all $n$ for some fixed constant $c(w, f)$, where (letting $\nu \| m$ denote $p^{\alpha} \mid m$ but $p^{\alpha+1} \nmid m$ for all $p^{\alpha}$ in the prime decomposition of $\nu$ )

$$
\begin{gathered}
\gamma(\nu)=\lim _{n \rightarrow \infty} \gamma(\nu, n)=\lim _{n \rightarrow \infty} \frac{\sum_{\substack{m \leqq n \\
\nu \| m}} w(m)}{\sum_{m \leqq n} w(m)}, \\
A(n)=\sum_{p^{\alpha} \leqq n} f\left(p^{\alpha}\right) \gamma\left(p^{\alpha}\right),
\end{gathered}
$$

and

$$
D^{2}(n)=\sum_{p^{\alpha} \leqq n}\left|f\left(p^{\alpha}\right)\right|^{2} \gamma\left(p^{\alpha}\right) .
$$

For a given weight function $w=w(m)$, we let $\Phi(w)$ represent 
the set of arithmetic functions such that (1.1) holds. We associate with a given family of weight functions $\mathscr{W}$ the set of arithmetic functions $\Phi(\mathscr{W})=\bigcap_{w \in \mathscr{W}} \Phi(w)$. Similarly for a given $f$ let $\Omega(f)$ denote the set of weight functions $w$ such that (1.1) holds, and for a collection of functions $\mathscr{F}$ define $\Omega(\mathscr{F})=\bigcap_{f \in \mathscr{T}} \Omega(f)$. When asserting that (1.1) holds, the constant $c$ may depend on both $f$ and $w$ (but not on $n$ ). A subset of $\Phi(\mathscr{W})$ is said to possess the Variance Property uniformly with respect to $\mathscr{W}$ if one constant $c$ can be used for all the functions involved. Similarly, a subset of $\Omega(\mathscr{F})$ is said to possess the Variance Property uniformly with respect to $\mathscr{F}$ if one constant $c$ can be used for all the functions involved. In this terminology the basic Variance Theorem cited in the introductory paragraph [1] concerning the set $\mathscr{C}$ of additive complex valued arithmetic functions (i.e., functions such that $f(m n)=f(m)+f(n)$ if $(m, n)=1)$ asserts that $\mathscr{A}$ possesses the Variance Property uniformly with respect to the weight function $w(m) \equiv 1$.

\section{Subfamilies of $\Omega(\mathscr{A})$. Let}

$\mathscr{W}_{0}=\left\{w(m): \gamma\left(p^{\alpha}, n\right) \leqq c_{0} \gamma\left(p^{\alpha}\right)\right.$ for all $p^{\alpha}$ and $n$, and for some $\left.c_{0}(w)\right\}$.

Theorem 2.1 gives two alternative sufficient conditions that will guarantee that a member of $\mathscr{W}_{0}$ possesses the Variance Property uniformly with respect to the set of additive functions; the remark at the end of this section shows that an averaging of one of these conditions is a necessary condition. Theorems 2.2 and 2.3 show that $w(m)=m^{r}$ (for any fixed real number $r$ ) and $w(m)=r^{m}$ (for some fixed $r, 0<r<1$ ), possess the Variance Property uniformly with respect to $\mathscr{A}$.

Lemma. Let $w \in \mathscr{W}_{0}$ and $f \in \mathscr{A}$. Then $f \in \Phi(w)$ if and only if

$$
\left|\sum_{\substack{p^{\alpha} \leqq n, q \beta \\ p \neq q}} f\left(p^{\alpha}\right) \overline{f\left(q^{\beta}\right)} T\left(p^{\alpha}, q^{\beta}, n\right)\right| \leqq c_{1} D^{2}(n)
$$

for all $n$ and some fixed $c_{1}(f)$, where

$$
\begin{aligned}
T\left(p^{\alpha}, q^{\beta}, n\right)= & \gamma\left(p^{\alpha} q^{\beta}, n\right)-\gamma\left(p^{\alpha}\right) \gamma\left(q^{\beta}, n\right)-\gamma\left(q^{\beta}\right) \gamma\left(p^{\alpha}, n\right) \\
& +\gamma\left(p^{\alpha}\right) \gamma\left(q^{\beta}\right) .
\end{aligned}
$$

If (2.1) holds for all $f \in \mathscr{A}$, then $\mathscr{A}$ possesses the Variance Property uniformly with respect to $w$ if and only if $c_{1}$ can be chosen independent of $f \in \mathscr{A}$. 
Proof. $\quad \sum_{m \leqq n} w(m)|f(m)-A(n)|^{2}=\left(R_{1}+R_{2}+R_{3}\right) \sum_{m \leqq n} w(m)$ where

$$
\begin{gathered}
R_{1}=\sum_{p^{\alpha} \leq n}\left|f\left(p^{\alpha}\right)\right|^{2} \gamma\left(p^{\alpha}, n\right), \\
R_{2}=\sum_{\substack{p^{\alpha} \leq n \\
\beta \leq\lfloor\log n \\
\log p}} f\left(p^{\alpha}\right) \overline{f\left(p^{\beta}\right)}\left(\gamma\left(p^{\alpha}\right) \gamma\left(p^{\beta}\right)-\gamma\left(p^{\alpha}\right) \gamma\left(p^{\beta}, n\right)-\gamma\left(p^{\beta}\right) \gamma\left(p^{\alpha}, n\right)\right),
\end{gathered}
$$

and

$$
R_{3}=\sum_{\substack{p^{\alpha} \leqq n, q^{\beta} \leqq n \\ p \neq q}} f\left(p^{\alpha}\right) \overline{f\left(q^{\beta}\right)} T\left(p^{\alpha}, q^{\beta}, n\right) .
$$

Now $w \in \mathscr{W}_{0}$ implies $\left|R_{1}\right| \leqq c_{0} D^{2}(n)$ and (by using Schwarz's inequality)

$$
\begin{aligned}
\left|R_{2}\right| & \leqq \max \left(1,2 c_{0}\right) \sum_{p^{\alpha} \leqq n}\left|f\left(p^{\alpha}\right)\right|^{2} \gamma\left(p^{\alpha}\right) \sum_{\beta \leqq\left[\frac{\log n}{\log p}\right]} \gamma\left(p^{\beta}\right) \\
& \leqq \max \left(1,2 c_{0}\right) D^{2}(n),
\end{aligned}
$$

which completes the proof.

THEOREM 2.1. Let $w \in \mathscr{W}_{0}$ be such that either

$$
\sum_{\substack{q \leq n \\ q \neq p}}\left|T\left(p^{\alpha}, q^{\beta}, n\right)\right| \leqq c_{2} \gamma\left(p^{\alpha}\right)
$$

for all $n$ and all $p^{\alpha} \leqq n$, for some constant $c_{2}$, or

$$
\sum_{\substack{p^{\alpha} \leq n, q^{\beta} \leq n \\ \gamma\left(p^{\alpha}\right) \neq 0, r\left(q^{\beta}\right) \neq 0 \\ p \neq q}} \frac{T^{2}\left(p^{\alpha}, q^{\beta}, n\right)}{\gamma\left(p^{\alpha}\right) \gamma\left(q^{\beta}\right)} \leqq c_{2}^{2}
$$

for all $n$. Then $w$ possesses the Variance Property uniformly with respect to $\mathscr{A}$.

The proof follows immediately by applying Schwarz's inequality in two different ways to the left hand side of (2.1).

THEOREM 2.2. The weight function $w(m)=m^{r}$, where $r$ is any fixed real number, possesses the Variance Property uniformly with respect to $\mathscr{A}$. For this weight function

$$
\gamma\left(p^{\alpha}\right)= \begin{cases}p^{\alpha r}\left(1-p^{r}\right) & \text { if } \quad r \leqq-1 \\ p^{-\alpha}\left(1-p^{-1}\right) & \text { if } \quad r \geqq-1\end{cases}
$$

Proof. Let

$$
\lambda(\nu, n)=\frac{\sum_{k \leq n} w(k)}{\sum_{k \leqq n} w(k)}=\nu^{r} \frac{\sum_{k \leq n / \nu} k^{r}}{\sum_{k \leq n} k^{r}}
$$


so that

$$
\gamma\left(p^{\alpha}, n\right)=\lambda\left(p^{\alpha}, n\right)-\lambda\left(p^{\alpha+1}, n\right)
$$

and (for $p \neq q$ )

$$
\begin{aligned}
\gamma\left(p^{\alpha} q^{\beta}, n\right)= & \lambda\left(p^{\alpha} q^{\beta}, n\right)-\lambda\left(p^{\alpha+1} q^{\beta}, n\right)-\lambda\left(p^{\alpha} q^{\beta+1}, n\right) \\
& +\lambda\left(p^{\alpha+1} q^{\beta+1}, n\right) .
\end{aligned}
$$

Using elementary calculus we obtain the following inequalities:

$$
\left.\begin{array}{rl}
\log x \\
\frac{x^{r+1}}{r+1}-\frac{1}{r+1} \\
\frac{x^{r+1}}{r+1}-2^{r} x^{r}
\end{array}\right\} \leqq \sum_{k \leqq x} k^{r} \leqq\left\{\begin{array}{lll}
r /(r+1) & \text { for } & r<-1 \\
1+\log x & \text { for } & r=-1 \\
\frac{x^{r+1}}{r+1} & \text { for } & -1<r<0 \\
\frac{x^{r+1}}{r+1}+x^{r} & \text { for } & r \geqq 0
\end{array}\right.
$$

(where the term $-2^{r} x^{r}$ may be omitted in the $r \geqq 0$ case if $x$ is an integer). For $r \geqq-1$ this result provides upper and lower bounds for $\lambda(\nu, n)$ which show that

$$
\lambda(\nu)=\lim _{n \rightarrow \infty} \lambda(\nu, n)=\left\{\begin{array}{lll}
\nu^{r} & \text { for } & r \leqq-1, \\
\nu^{-1} & \text { for } & r \geqq-1,
\end{array}\right.
$$

where, for $r<-1$, the result follows from the convergence of $\sum k^{r}$. (2.10) and (2.7) now yield (2.5). Also, the upper bounds on $\lambda(\nu, n)$ show that

$$
\gamma(\nu, n) \leqq \lambda(\nu, n) \leqq \frac{1}{2} c_{0} \lambda(\nu)
$$

for some $c_{0}=c_{0}(r)$. Thus we see that $w \in \mathscr{W}_{0}$ since

$$
\lambda\left(p^{\alpha}\right) \leqq 2 \gamma\left(p^{\alpha}\right)
$$

We note that $\lambda\left(p^{\alpha} q^{\beta}\right)=\lambda\left(p^{\alpha}\right) \lambda\left(q^{\beta}\right)$, and hence as a result of (2.2), (2.11) and (2.12)

$$
\begin{aligned}
\sum_{\substack{p^{\alpha} \leqq n, q^{\beta} \leqq n \\
p^{\alpha} q^{\beta}>n \\
p \neq q}} \frac{T^{2}\left(p^{\alpha}, q^{\beta}, n\right)}{\gamma\left(p^{\alpha}\right) \gamma\left(q^{\beta}\right)} & \leqq 4\left(1+c_{0}\right)^{2} \sum_{\substack{p^{\alpha} \leqq n, q^{\beta} \leqq n \\
p^{\alpha} q^{\beta}>n}} \lambda\left(p^{\alpha}\right) \lambda\left(q^{\beta}\right) \\
& \leqq 4\left(1+c_{0}\right)^{2} \sum_{\substack{p^{\alpha} \leqq n, q^{\beta} \leqq n \\
p^{\alpha} q^{\beta}>n}} \frac{1}{p^{\alpha} q^{\beta}}
\end{aligned}
$$

which is known to be bounded [1]. All that remains to verify (2.4) is to show 


$$
S=\sum_{\substack{p_{q} q^{\beta} \leq n \\ p \neq q}} \frac{T^{2}\left(p^{\alpha}, q^{\beta}, n\right)}{\gamma\left(p^{\alpha}\right) \gamma\left(q^{\beta}\right)}
$$

is bounded. Then the desired result will follow from Theorem 2.1. For $r<-1$ we note that

$$
S \leqq 4\left(1+c_{0}\right)^{2} \sum_{\substack{p^{\alpha} q^{\beta} \leqq n \\ p \neq q}} \lambda\left(p^{\alpha}\right) \lambda\left(q^{\beta}\right) \leqq 8\left(1+c_{0}\right)^{2} \sum_{k \leqq n} k^{r}
$$

which is bounded. In view of (2.6), (2.7) and (2.8), for $r \geqq-1$ and $p \neq q$ we have

$$
\begin{aligned}
U= & T\left(p^{\alpha}, q^{\beta}, n\right) \sum_{k \leqq n} k^{r} \\
= & p^{r \alpha} q^{r \beta} \sum_{k \leqq n)\left(p^{\alpha} q^{\beta)}\right.} k^{r}-p^{r(\alpha+1)} q^{r \beta} \sum_{k \leqq n /\left(p^{\alpha+1} q^{\beta)}\right.} k^{r} \\
& -p^{r \alpha} q^{r(\beta+1)} \sum_{k \leqq n /\left(p^{\alpha} q^{\beta+1}\right)} k^{r}+p^{r(\alpha+1)} q^{r(\beta+1)} \sum_{k \leqq n /\left(p^{\alpha+1} q^{\beta+1}\right)} k^{r} \\
& -p^{\alpha}\left(1-p^{-1}\right) q^{r \beta} \sum_{k \leqq n \mid q^{\beta}} k^{r}+p^{-\alpha}\left(1-p^{-1}\right) q^{r(\beta+1)} \sum_{k \leqq n /\left(\beta^{\beta+1}\right)} k^{r} \\
& -q^{-\beta}\left(1-q^{-1}\right) p^{r \alpha} \sum_{k \leqq n \mid p^{\alpha}} k^{r}+q^{-\beta}\left(1-q^{-1}\right) p^{r(\alpha+1)} \sum_{k \leqq n /\left(p^{\alpha+1}\right)} k^{r} \\
& +p^{-\alpha} q^{-\beta}\left(1-p^{-1}\right)\left(1-q^{-1}\right) \sum_{k \leqq n} k^{r} .
\end{aligned}
$$

Using the inequalities of (2.9) on (2.14) to find upper and lower bounds for $U$, and then applying (2.9) to the factor $\sum k^{r}$ of $U$ in order to obtain upper and lower bounds for $T\left(p^{\alpha}, q^{\beta}, n\right)$, we find after lengthy but straightforward calculation that, for $n \geqq 2$ and $p \neq q$

$$
\left|T\left(p^{\alpha}, q^{\beta}, n\right)\right| \leqq \begin{cases}\frac{c_{3}}{p^{\alpha} q^{\beta} \log n} & \text { for } \quad r=-1 \\ \frac{c_{3}\left(p^{\alpha} q^{\beta}\right)^{r}}{n^{r+1}} & \text { for } \quad-1<r<0 \\ c_{3} / n & \text { for } \quad r \geqq 0\end{cases}
$$

for some $c_{3}(\mathrm{r})$. Actually, for the case where $r=-1$, the calculations leading to (2.15) assume $p^{\alpha+1} q^{\beta+1} \leqq n$, since the appropriate inequality of (2.9) used in bounding $U$ assumes $1+\log n / p^{\alpha+1} q^{\beta+1} \geqq 0$. But we may only assume $p^{\alpha} q^{\beta} \leqq n$ in showing $S$ is bounded. However, if $p^{\alpha} q^{\beta} \leqq n<p^{\alpha+1} q^{\beta+1}$, then

$$
\begin{aligned}
& \left|\frac{1}{p^{\alpha+1} q^{\beta+1}}\left(1+\log \frac{n}{p^{\alpha+1} q^{\beta+1}}\right)\right| \\
& \quad \leqq \frac{1}{p^{\alpha+1} q^{\beta+1}}\left|1-\log \frac{p^{\alpha} q^{\beta}}{n} p q\right| \leqq \frac{1}{p^{\alpha} q^{\beta}} .
\end{aligned}
$$

Similarly, all the other special cases do not affect the result given 
by (2.15).

For $r=-1,(2.13)$ and (2.15) yield

$$
S \leqq \frac{4 c_{3}^{2}}{\log ^{2} n} \sum_{p^{\alpha} q^{\beta} \leqq n} \frac{1}{p^{\alpha} q^{\beta}} \leqq \frac{4 c_{3}^{2}}{\log ^{2} n}\left(\sum_{p^{\alpha} \leqq n} p^{-\alpha}\right)^{2}=\frac{O(\log \log n)^{2}}{\log ^{2} n}
$$

which is bounded.

$$
\begin{aligned}
& \text { For }-1<r<0,(2.13) \text { and (2.15) show } \\
& \qquad S \leqq O\left(n^{-2 r-2}\right) \sum_{\substack{p^{\alpha} q \beta \leq n \\
p \neq q}}\left(p^{\alpha} q^{\beta}\right)^{1+2 r} \leqq O\left(n^{-2 r-2}\right) \sum_{k \leqq n} k^{1+2 r},
\end{aligned}
$$

which is bounded $\left((2.9)\right.$ yields this for $-1<r<-1 / 2$, and $k^{1+2 r} \leqq$ $n^{1+2 r}$ implies the bound when $\left.-1 / 2 \leqq r<0\right)$.

For $r \geqq 0,(2.13)$ and (2.15) show

$$
S \leqq O\left(n^{-2}\right) \sum_{\substack{p^{\alpha} q \leqq n \\ p \neq q}} p^{\alpha} q^{\beta} \leqq O\left(n^{-1}\right) \sum_{k \leqq n} 1=O(1) .
$$

Thus $S$ is bounded for all values of $r$, which finishes the proof of the theorem.

THEOREM 2.3. The weight function $w(m)=r^{m}$, where $r$ is a fixed number, $0<r<1$, possesses the Variance Property uniformly with respect to $\mathscr{A}$. For this weight function,

$$
\gamma\left(p^{\alpha}\right)=r^{p^{\alpha}-1} \frac{1-r}{1-r^{p^{\alpha}}} \frac{1-r^{p^{\alpha+1}}-p^{\alpha}}{1-r^{p^{\alpha+1}}} .
$$

Proof. Let

$$
\lambda(\nu, n)=\frac{\sum_{\substack{m \leq n \\ \nu / m}} w(m)}{\sum_{m \leqq n} w(m)}=\frac{\sum_{k \leq n / \nu}\left(r^{\nu}\right)^{k}}{\sum_{m \leq n} r^{m}}=r^{\nu-1} \frac{1-r}{1-r^{\nu}} \frac{1-r^{\nu[n / \nu]}}{1-r^{n}} .
$$

Now $\gamma\left(p^{\alpha}\right)=\lim _{n \rightarrow \infty}\left(\lambda\left(p^{\alpha}, n\right)-\lambda\left(p^{\alpha+1}, n\right)\right)$ yields (2.16). Also $\gamma(\nu, n) \leqq$ $\lambda(\nu, n) \leqq r^{\nu-1}$ and (2.16) imply

$$
(1-r) \gamma\left(p^{\alpha}, n\right) \leqq(1-r) r^{p^{\alpha}-1} \leqq \gamma\left(p^{\alpha}\right) \leqq r^{p^{\alpha}-1},
$$

which shows that $w \in \mathscr{W}_{0}$ and (cf. (2.2)) $\left|T\left(p^{\alpha}, q^{\beta}, n\right)\right| \leqq 4 r^{p^{\alpha}+q^{\beta}-2}$. Thus

$$
\sum_{\substack{p^{\alpha} \leqq n, q \\ p \neq q}} \frac{T^{2}\left(p^{\alpha}, q^{\beta}, n\right)}{\gamma\left(p^{\alpha}\right) \gamma\left(q^{\beta}\right)}=O\left(\sum_{p^{\alpha} \leqq n} r^{p^{\alpha}}\right)^{2}=O(1) .
$$

The desired result now follows from Theorem 2.1.

REMaRK. Assume $w \in \mathscr{W}_{0}$. Then a necessary condition for $w$ 
to belong to $\Omega(\mathscr{A})$ is

$$
\left|\sum_{p^{\alpha} \leqq n, q} \sum_{q^{\beta}} T\left(p^{\alpha}, q^{\beta}, n\right)\right| \leqq c_{1} \sum_{p^{\alpha} \leqq n} \gamma\left(p^{\alpha}\right) .
$$

This follows from the lemma by use of the additive function determined by $f\left(p^{\alpha}\right)=1$ for all $p^{\alpha}$.

3. The Variance Property for nonadditive functions. In this section attention is restricted to weight functions which possess the Variance Property with respect to $\mathscr{X}$. The reason for doing so is the fact that any arithmetic function $g$ can be written as $g=f+h$ where

$$
f(m)=\sum_{p^{\alpha}|| m} g\left(p^{\alpha}\right) ;
$$

then $A(n)$ and $D^{2}(n)$ are the same for $g$ and $f$, and $f$ is additive. Thus, the results of $\S 2$ apply to $f$. In the rest of this section $f$ will always represent the purely "additive" part of $g$ while $h$ will represent the purely "nonadditive" part of $g$.

Theorem 3.1 gives a necessary and sufficient global condition (in the sense that it involves the average value of $|h|$ ) for $h$ to satisfy in order to have $g$ possess the Variance Property with respect to a weight function $w$. Its corollary provides a local sufficient condition (in the sense that it involves the specific values of $h$ ). Remark 3.1 shows that in general this local sufficient condition cannot be substantially improved upon, and that in general there is a "gap" between the local sufficient condition and a local necessary condition. However, Remark 3.2 shows that in specific cases the local sufficient condition of the corollary can be improved, and the gap between it and a local necessary condition can be reduced almost to the difference between a small " $O$ " relation and a big " $O$ " relation.

Theorem 3.1. Assume $w \in \Omega(\mathscr{A})$. Then $g \in \Phi(w)$ if and only if

$$
\sum_{m \leqq n} w(m)|h(m)|^{2}=O\left(D^{2}(n) \sum_{m \leqq n} w(m)\right) .
$$

The proof follows directly from (1.1).

Corollary. Assume $w \in \Omega(\mathscr{A})$. Then $g \in \Phi(w)$ if

$$
h(m)=O(D(m)) \text {. }
$$

REMARK 3.1. Consider the weight function $w(m) \equiv 1$. Then $|h(m)|=O(\sqrt{m} D(m))$ is a necessary condition for $g=f+h$ to belong 
to $\Phi(w)$. For if there were a sequence of integers $m_{k} \rightarrow \infty$ such that

$$
\frac{\sum_{m \leqq m_{k}}|h(m)|^{2}}{m_{k} D^{2}\left(m_{k}\right)} \geqq \frac{\left|h\left(m_{k}\right)\right|^{2}}{m_{k} D^{2}\left(m_{k}\right)} \longrightarrow \infty,
$$

this would contradict the fact that $g \in \Phi(w)$.

Now if we examine the function

$$
g(m)= \begin{cases}4 & \text { if } \quad m=2 \\ \sqrt{m} & \text { if } \quad m=15^{k} \\ 0 & \text { otherwise }\end{cases}
$$

we find that $A(n)=1, D^{2}(n)=4$, and $g \in \Phi(w)$. Thus the necessary condition $|h(m)|=O(\sqrt{m} D(m))$ cannot be improved.

On the other hand, if we let $f$ be the additive function determined by setting $f\left(p^{\alpha}\right)=p^{-\alpha / 2}$ so that $1 / 8 \leqq D^{2}(n)=O(1)$, and define

$$
h(m)= \begin{cases}0 & \text { for } m=p^{\alpha} \\ m^{a} D(m) & \text { otherwise }\end{cases}
$$

for $a>0$ fixed, then it follows from Theorem 3.1 that $g=f+h$ does not belong to $\Phi(w)$. To see this, note that

$$
\sum_{m \leqq n}|h(m)|^{2} \geqq \frac{1}{8} \sum_{\substack{m \leq n \\ m \neq p^{\alpha}}} m^{2 a} \geqq \delta n^{1+2 a}
$$

for some fixed constant $\delta>0$. Thus we see the sufficient condition (3.3) cannot be substantially improved either.

REMARK 3.2. Consider the weight function $w(m)=r^{m}, 0<r<1$. Then $|h(m)|=O\left(r^{-m / 2} D(m)\right)$ is a necessary condition for $g$ to belong to $\Phi(w)$ since Theorem 3.1 and the existence of a sequence of integers $m_{k} \rightarrow \infty$ such that

$$
\frac{\sum_{m \leqq m_{k}} r^{m}|h(m)|^{2}}{D^{2}\left(m_{k}\right) \sum_{m \leqq m_{k}} r^{m}} \geqq \frac{(1-r) r^{m_{k}}\left|h\left(m_{k}\right)\right|^{2}}{D^{2}\left(m_{k}\right)} \longrightarrow \infty
$$

would imply that $g$ did not belong to $\Phi(w)$.

On the other hand, $|h(m)|=O\left(\alpha(m) r^{-m / 2} D(m)\right)$, where $a(m) \geqq 0$ and $\sum a(m)<\infty$, is a sufficient condition for $g$ to belong to $\Phi(w)$, since in this case

$$
\sum_{m \leqq n} r^{m}|h(m)|^{2}=O\left(D^{2}(n) \sum_{m \leqq n} a(m)\right)=O\left(D^{2}(n)\right) .
$$


Thus we see that for these weight functions the sufficient condition (3.3) can be improved, and the difference between the necessary condition and the sufficient condition is almost the difference between a small " $O$ " relation and a big " $O$ " relation.

\section{REFERENCES}

1. J. Kubilius, Probabilistic Methods in the Theory of Numbers, Translations of Mathematical Monographs, Amer. Math. Soc. Vol. 11, Providence, R. I., 1964.

Received August 26, 1975.

Baruch College, City University of New York 



\title{
PACIFIC JOURNAL OF MATHEMATICS
}

\author{
EDITORS
}

\author{
RICHARD ARENS (Managing Editor) \\ University of California \\ Los Angeles, California 90024
}

\author{
R. A. Beaumont \\ University of Washington \\ Seattle, Washington 98105
}

J. DugundjI

Department of Mathematics

University of Southern California

Los Angeles, California 90007

D. Gilbarg and J. Milgram

Stanford University

Stanford, California 94305

\section{ASSOCIATE EDITORS}
E. F. BECKENBACH
B. H. NEUMANN
F. WOLF
K. Yoshida

\section{SUPPORTING INSTITUTIONS}

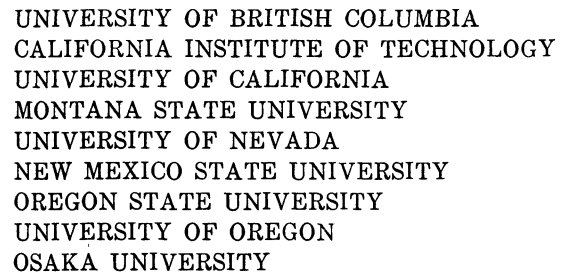

UNIVERSITY OF BRITISH COLUMBIA CALIFORNIA INSTITUTE OF TECHNOLOGY UNIVERSITY OF CALIFORNIA MONTANA STATE UNIVERSITY UNIVERSITY OF NEVADA NEW MEXICO STATE UNIVERSITY OREGON STATE UNIVERSITY UNIVERSITY OF OREGON OSAKA UNIVERSITY

\author{
UNIVERSITY OF SOUTHERN CALIFORNIA \\ STANFORD UNIVERSITY \\ UNIVERSITY OF HAWAII \\ UNIVERSITY OF TOKYO \\ UNIVERSITY OF UTAH \\ WASHINGTON STATE UNIVERSITY \\ UNIVERSITY OF WASHINGTON

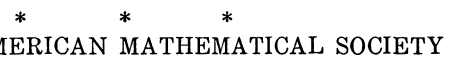

The Supporting Institutions listed above contribute to the cost of publication of this Journal, but they are not owners or publishers and have no responsibility for its content or policies.

Mathematical papers intended for publication in the Pacific Journal of Mathematics should be in typed form or offset-reproduced, (not dittoed), double spaced with large margins. Please do not use built up fractions in the text of your manuscript. You may however, use them in the displayed equations. Underline Greek letters in red, German in green, and script in blue. The first paragraph or two must be capable of being used separately as a synopsis of the entire paper. Items of the bibliography should not be cited there unless absolutely necessary, in which case they must be identified by author and Journal, rather than by item number. Manuscripts, in triplicate, may be sent to any one of the editors. Please classify according to the scheme of Math. Reviews, Index to Vol. 39. All other communications should be addressed to the managing editor, or Elaine Barth, University of California, Los Angeles, California, 90024.

The Pacific Journal of Mathematics expects the author's institution to pay page charges, and reserves the right to delay publication for nonpayment of charges in case of financial emergency.

100 reprints are provided free for each article, only if page charges have been substantially paid. Additional copies may be obtained at cost in multiples of 50 .

The Pacific Journal of Mathematics is issued monthly as of January 1966. Regular subscription rate: $\$ 72.00$ a year (6 Vols., 12 issues). Special rate: $\$ 36.00$ a year to individual members of supporting institutions.

Subscriptions, orders for back numbers, and changes of address should be sent to Pacific Journal of Mathematics, 103 Highland Boulevard, Berkeley, California, 94708.

PUBLISHED BY PACIFIC JOURNAL OF MATHEMATICS, A NON-PROFIT CORPORATION

Printed at Kokusai Bunken Insatsusha (International Academic Printing Co., Ltd.), 8-8, 3-chome, Takadanobaba, Shinjuku-ku, Tokyo 160, Japan.

Copyright (C) 1975 by Pacific Journal of Mathematics Manufactured and first issued in Japan 


\section{Pacific Journal of Mathematics}

\section{Vol. 63, No. 2 \\ April, 1976}

Joseph Anthony Ball and Arthur R. Lubin, On a class of contractive perturbations

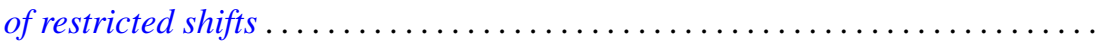

Joseph Becker and William C. Brown, On extending higher derivations generated

by cup products to the integral closure .......................

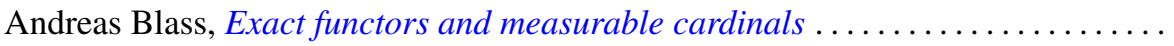

Joseph Eugene Collison, A variance property for arithmetic functions . . . . . . . . . .

Craig McCormack Cordes, Quadratic forms over nonformally real fields with a

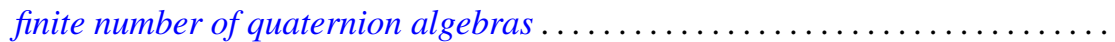

Freddy Delbaen, Weakly compact sets in $H^{1} \ldots \ldots \ldots \ldots \ldots \ldots \ldots \ldots \ldots$

G. D. Dikshit, Absolute Nörlund summability factors for Fourier series ..........

Edward Richard Fadell, Nielsen numbers as a homotopy type invariant. . ........

Josip Globevnik, Analytic extensions of vector-valued functions . . . . . . . . . . . .

Robert Gold, Genera in normal extensions . . . . . . . . . . . . . . . . . . . 389

Solomon Wolf Golomb, Formulas for the next prime

Robert L. Griess, Jr., The splitting of extensions of $S L(3,3)$ by the vector space

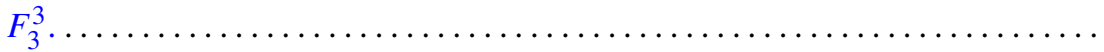

Thomas Alan Keagy, Matrix transformations and absolute summability .........

Kazuo Kishi, Analytic maps of the open unit disk onto a Gleason part.

Kwangil Koh, Jiang Luh and Mohan S. Putcha, On the associativity and commutativity of algebras over commutative rings . ..... . .

James C. Lillo, Asymptotic behavior of solutions of retarded differential difference equations.

John Alan MacBain, Local and global bifurcation from normal eigenvalues ..

Anna Maria Mantero, Sets of uniqueness and multiplicity for $L^{p}$

J. F. McClendon, Embedding metric families

L. Robbiano and Giuseppe Valla, Primary powers of a prime ideal .

Wolfgang Ruess, Generalized inductive limit topologies and barrelledness

properties.

Judith D. Sally, Bounds for numbers of generators of Cohen-Macaulay ideals

Helga Schirmer, Mappings of polyhedra with prescribed fixed points and fixed point indices.

Cho Wei Sit, Quotients of complete multipartite graphs

S. Sznajder and Zbigniew Zielezny, Solvability of convolution equations in $\mathscr{K}_{p}^{\prime}$,

$p>1$.

Mitchell Herbert Taibleson, The existence of natural field structures for finite

dimensional vector spaces over local fields

William Yslas Vélez, A characterization of completely regular fields

P. S. Venkatesan, On right unipotent semigroups ..............

Kenneth S. Williams, A rational octic reciprocity law ............

Robert Ross Wilson, Lattice orderings on the real field .......... 